\title{
COMPARISON OF FORCE-BASED AND DISPLACEMENT- BASED DESIGN APPROACHES FOR RC COUPLED WALLS IN NEW ZEALAND
}

\author{
Matthew J. Fox ${ }^{1}$, Timothy J. Sullivan² and Katrin Beyer ${ }^{3}$
}

\begin{abstract}
SUMMARY
Reinforced concrete coupled walls are a common lateral load resisting system used in multi-storey buildings. The effect of the coupling beams can improve seismic performance, but at the same time adds complexity to the design procedure. A case study coupled wall building is designed using Force-Based Design (FBD) and Direct Displacement-Based Design (DDBD) and in the case of the latter a step by step design example is provided. Distributed plasticity fibre-section beam element numerical models of the coupled walls are developed in which coupling beams are represented by diagonal truss elements and experimental results are used to confirm that this approach can provide a good representation of hysteretic behaviour. The accuracy of the two different design methods is then assessed by comparing the design predictions to the results of non-linear time-history analyses. It is shown that the DDBD approach gives an accurate prediction of inter-storey drift response. The FBD approach, in accordance with NZS1170.5 and NZS3101, is shown to include an impractical procedure for the assignment of coupling beam strengths and code equations for the calculation of coupling beam characteristics appear to include errors. Finally, the work highlights differences between the P-delta considerations that are made in FBD and DDBD, and shows that the code results are very sensitive to the way in which P-delta effects are accounted for.
\end{abstract}

\section{INTRODUCTION}

In the seismic design of structures, Force-Based Design procedures are most commonly adopted by design codes. In New Zealand this is reflected in the two standards used for the seismic design of reinforced concrete (RC) structures; NZS1170.5-Structural Design Actions Part 5: Earthquake Actions [2004] and NZS3101-Concrete Structures Standard [2006]. It is now known that most code FBD approaches are based on a number of flawed concepts as explained by Priestley [1993, 2003] and these flaws can potentially lead to non-conservative designs. As a result, Displacement-Based Design (DBD) procedures have been developed to correct these issues. The development of DBD procedures is further motivated by the increasing focus on Performance-Based Earthquake Engineering, in which more robust performance levels are established in comparison to the traditional prescriptive approaches and design solutions are tailored to meet client needs. The performance levels are typically based on damage to the structural and non-structural elements, which in turn are directly related to displacements and deformations (or to floor accelerations in the case of acceleration sensitive non-structural elements and contents).

This paper considers the Direct Displacement-Based Design method of Priestley et al. [2007] and the Force-Based Design approach, in accordance with the New Zealand standards, and their application to the design of RC coupled walls. RC coupled walls can be used to resist part, or all, of the lateral loads induced in a building from wind or seismic actions.

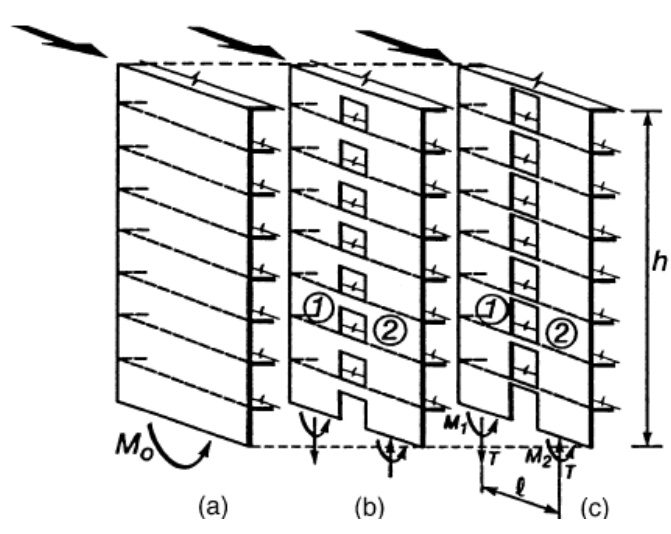

Figure 1: Mechanisms resisting the overturning moment in RC coupled walls from Paulay [2002].

In some respects they are superior in performance to equivalent cantilever wall systems as they resist overturning moments through two different mechanisms (i) the flexural resistance of the individual walls and (ii) the axial force couple generated in the walls by the coupling beams. This is demonstrated in Figure 1, where $M_{1}$ and $M_{2}$ are the moments resisted by the two individual walls and $T$ and $l$ are the axial force and lever arm respectively, which resist the remainder of the overturning moment. The other major point of interest regarding the seismic response of coupled walls is that for typical geometric configurations the ductility demand on the

\footnotetext{
${ }^{1}$ ROSE Programme, UME School, IUSS Pavia, Italy.

${ }^{2}$ Department of Civil Engineering and Architecture, University of Pavia, Italy and EUCENTRE, Pavia, Italy.

${ }^{3}$ School of Architecture, Civil and Environmental Engineering, École Polytechnique Fédérale de Lausanne, Switzerland.
} 
coupling beams is large. Paulay [1969] showed that conventionally reinforced coupling beams were not capable of sustaining such large ductility demands and as such the concept of diagonally reinforced coupling beams was developed [Paulay \& Binney, 1974]. Only diagonally reinforced coupling beams are examined in this work, but the design considerations made here should also apply to other coupling beam configurations that exhibit, under inelastic reversed cyclic loading, behaviour that can be approximated by a bilinear envelope with positive post-yield stiffness.

To allow for a comparison between the two design methods, a simple case study structure (described in Section 2) is designed using both DBD and FBD (as described in Sections 3 and 4). The likely response of the designed structures is then examined using non-linear time-history analyses, with the main focus placed on how accurately each design method can estimate the displacement and deformation demands (Sections 5 and 6). It should be noted that the intent of design codes may not necessarily be to provide an accurate prediction of structural response, but instead to provide a means of ensuring structures satisfy the minimum performance objectives of the codes, i.e., they may have additional conservatism built in. It is the authors' opinion that an optimal seismic design approach should seek to accurately predict structural response such that the design method leads to similar levels of risk for different designs. Following this comparison the significance of P-delta effects on the response of coupled wall structures and how they are accounted for in NZS1170.5 [2004] is examined (Section 7). Conclusions are made and a list of symbols is provided at the end of the paper.

\section{CASE STUDY STRUCTURE}

The simple case study structure to be designed is shown in Figure 2. It is seven storeys tall, with each storey having a height of $3.4 \mathrm{~m}$. The floor area is $625 \mathrm{~m}^{2}$ and the distributed seismic mass of each level is taken to be $10 \mathrm{kPa}$, giving a seismic mass at each floor level of 637t. In the direction being considered, two coupled walls each resist half of the lateral loads. In the perpendicular direction it is assumed there is another lateral load resisting system, independent of the coupled walls. The majority of the gravity loads are carried by gravity-only columns, which do not contribute to lateral load resistance. The remaining gravity loads are carried by the coupled walls, with each individual wall supporting a weight of $300 \mathrm{kN}$ per floor level.

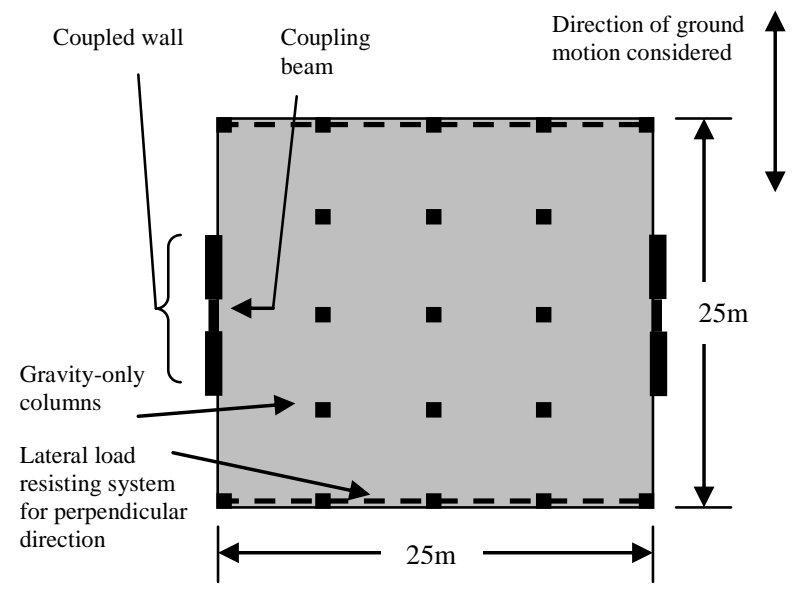

Figure 2: Plan view of case study structure.
It is assumed that through a combination of architectural restraints and preliminary sizing of members, the following dimensions for the walls and coupling beams are to be used in design; coupling beam thickness, $t_{C B}=200 \mathrm{~mm}$, coupling beam depth, $h_{C B}=800 \mathrm{~mm}$, coupling beam span, $L_{C B}=2000 \mathrm{~mm}$, wall thickness, $t_{w}=250 \mathrm{~mm}$ and wall length, $L_{w}=4000 \mathrm{~mm}$. The plan view and elevation of the case study structure are shown in Figure 2 and Figure 3 respectively.

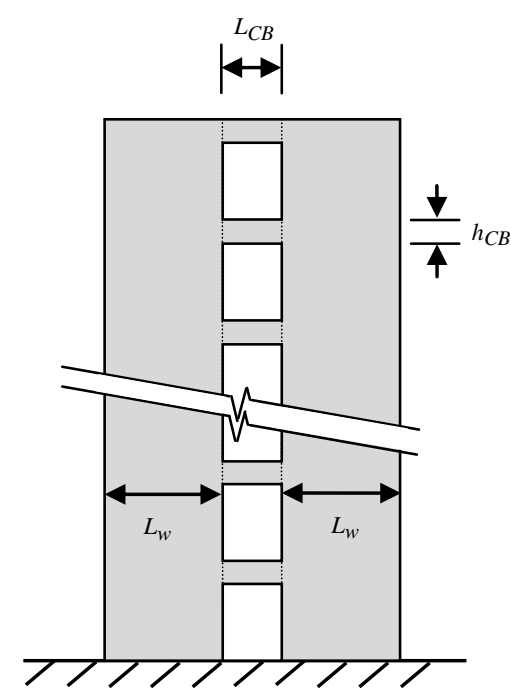

Figure 3: Elevation of a coupled wall in case study structure.

The material properties to be used in the design are provided in Table 1.

Table 1. Material properties for design.

\begin{tabular}{|c|c|c|}
\hline Concrete & $f_{c}^{\prime}(\mathrm{MPa})$ & 35 \\
\hline \multirow{3}{*}{ Reinforcing } & $f_{y}(\mathrm{MPa})$ & 500 \\
\cline { 2 - 3 } & $f_{u} / f_{y}$ & 1.3 \\
\cline { 2 - 3 } & $\varepsilon_{s, u}$ & $10 \%$ \\
\hline
\end{tabular}

The structure is assumed to be on a site with soil class D and a hazard factor of $Z=0.4$ (NZS1170.5, 2004). The importance level is two $\left(R_{u}=1.0\right)$, corresponding to 'normal structures,' and there are no near fault effects $(N(T, D)=1.0)$. The elastic site hazard acceleration spectrum $C(T)$ is then found from Equation 1.

$$
C(T)=C_{h}(T) Z R N(T, D)
$$

where $C_{h}(T)$ is the appropriate spectral shape factor for soil class D found from NZS1170.5 [2004]. This gives the design spectra for pseudo-acceleration and displacement shown in Figure 4 and Figure 5 respectively. The displacement spectrum is derived from the acceleration spectrum using the simple relationship $S D=P S A / \omega^{2}$, where $S D$ and $P S A$ are spectral displacement and pseudo spectral acceleration respectively and $\omega$ is the circular frequency $(=2 \pi / T)$. Also shown in the two figures are the response spectra for ten different real accelerograms to be used in the non-linear timehistory analyses (later in Section 5) along with the mean response spectra. 


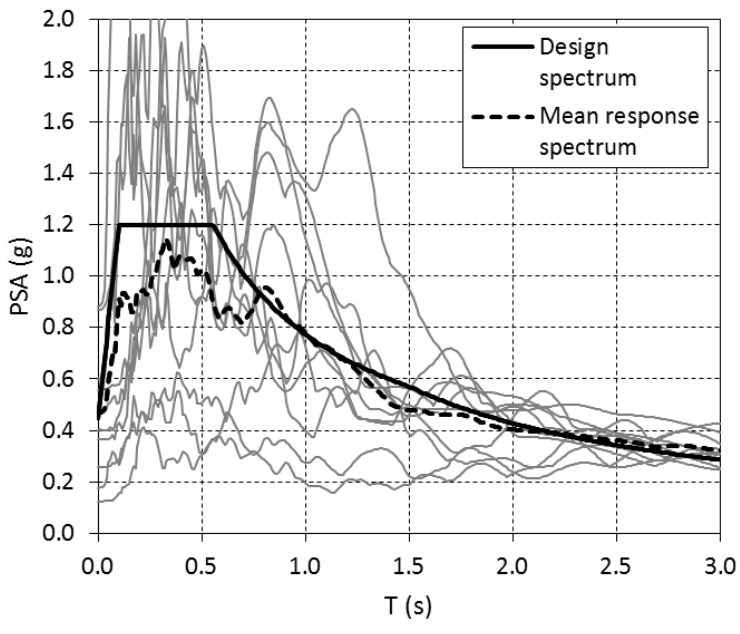

Figure 4: Design pseudo-acceleration spectrum and response spectra for accelerograms used in NTHA.

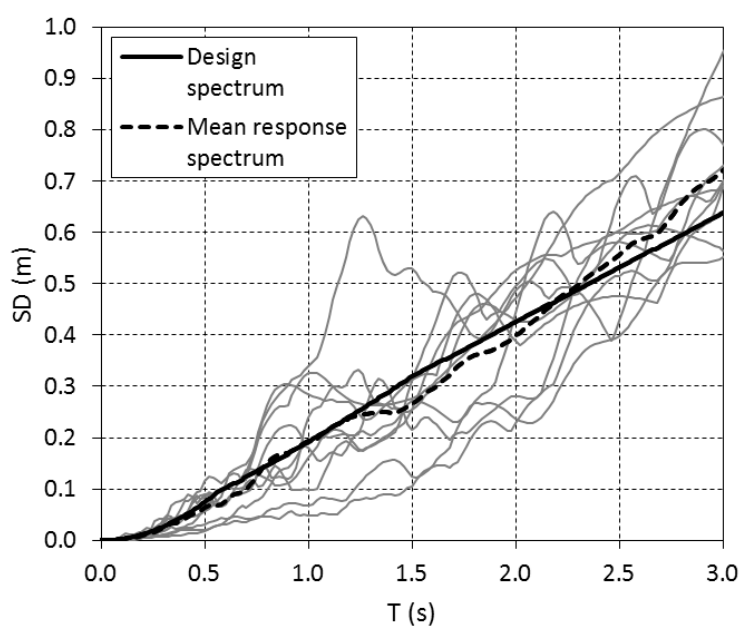

Figure 5: Design displacement spectrum and response spectra for accelerograms used in NTHA.

\section{DISPLACEMENT-BASED DESIGN}

\subsection{Overview of Direct Displacement-Based Design}

The fundamental approach of Direct Displacement-Based Design from Priestley et al. [2007] can be explained with reference to Figure 6. In the first part (a), the multi-degree-offreedom (MDOF) structure is converted to an equivalent single-degree-of-freedom (SDOF) system, with an effective mass, $m_{e}$, and an effective height, $H_{e}$. In the next part (b), the SDOF system is further characterised by determining the yield displacement, $\Delta_{y}$, and design displacement, $\Delta_{d}$, and these in turn give the displacement ductility demand, $\mu$. The effective stiffness $K_{e}$, is also shown in Figure 6 (b), but this is not determined until the final step. In the third part (c), the ductility factor is used to determine an equivalent viscous damping (EVD) ratio. This is a function of ductility and will vary depending on the structural system and its corresponding hysteretic behaviour. In the final part (d), the design displacement spectrum is reduced by a factor dependent on the level of EVD. Using the reduced displacement spectrum, the design displacement is used to determine the effective period, $T_{e}$. This is then used to calculate the effective stiffness and subsequently the design base shear of the SDOF system.
For most buildings, the majority of the design effort will go into converting the MDOF structure into an SDOF representation along with the necessary parameters to fully characterise the system. The required strength of structural elements can then be determined through various means, however, typically this can be done through simple equilibrium considerations in conjunction with capacity design principles. The exact manner in which this is done will vary depending on the structural system and this work will focus on the procedure for coupled walls. Interested readers should refer to Priestley et al. [2007] and Sullivan et al. [2012] for guidelines specific to other structural systems.

An important point regarding the general approach to DDBD is the consideration of accidental mass eccentricity, or lack thereof. NZS1170.5 requires the designer to consider an accidental eccentricity of $10 \%$ of the plan dimension orthogonal to the direction of loading. Priestley et al. [2007] do not recommend the consideration of accidental mass eccentricities and therefore it is not included in DDBD. To allow for a fair comparison, the accidental mass eccentricity is neglected in both the DDBD and FBD of the case study structure. This could reflect the situation where the lateral load system in the perpendicular direction provides a high level of torsional resistance. In this case the effect of the accidental mass eccentricity on the coupled walls would be negligible.

\subsection{Application of DDBD to coupled walls}

The fundamental procedure described in Section 3.1 can be broken down in to a step-by-step procedure specific to coupled walls. This has been done by Priestley et al. [2007] and is reproduced here for the case study structure. In some steps the procedure has been slightly modified to meet the requirements of the displacement-based design model code DBD12 [Sullivan et al, 2012] and match the work of Fox [2013]. The step-by-step procedure is as follows:

\section{Step 1- Selection of geometry and coupling ratio}

The length of the walls, coupling beam depth and coupling beam span must be defined at the start of the procedure. Like all designs, this will need to be based on experience or require some iteration until the preferred geometry is found. For coupled walls it is likely that the geometry may also need to meet rather strict architectural/functionality requirements as they are often incorporated into service cores in buildings.

The designer should then choose a coupling ratio, $\beta$, that defines the proportion of overturning moment to be resisted by the coupling mechanism. This can be expressed by Equation 2 . Selection of the coupling ratio at the start of the design process recognises the point made by Paulay [2002] that the distribution of strength throughout a structure should be the designer's choice. In this design example a coupling ratio of 0.35 is selected, and limiting the value helps ensure that the axial forces in the walls remain within acceptable limits (taken as $0.2 f^{\prime}{ }_{c} A_{g}$ in compression and $0.2 f_{y} A_{s}$ in tension). It should be noted that the ability to control the axial force in the walls in this manner does not occur in FBD and instead the axial forces in the walls are only influenced by changes in geometry.

$$
\beta=\left(\sum_{i=1}^{n} V_{C B i}\right)\left(L_{C B}+L_{W}\right) / M_{\text {OTM }}
$$




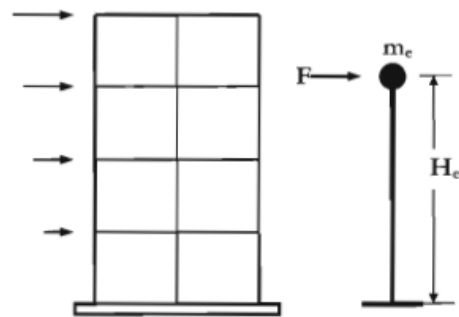

(a) SDOF Simulation

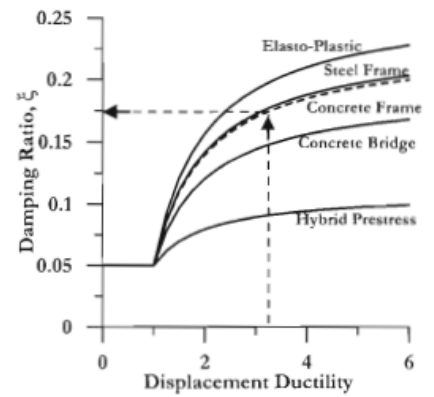

(c) Equivalent damping vs. ductility

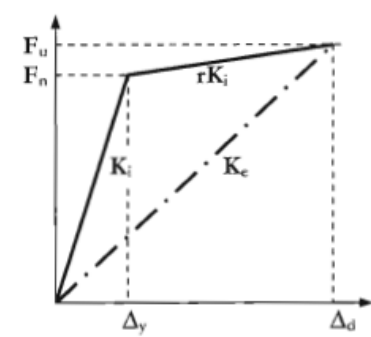

(b) Effective Stiffness $\mathrm{K}_{\mathrm{e}}$

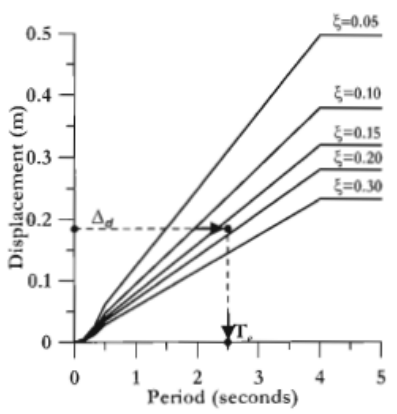

(d) Design Displacement Spectra

Figure 6: Fundamentals of Direct Displacement-Based Design from Priestley et al. [2007].

\section{Step 2-Determine height of contraflexure}

The second step involves computation of the expected height of contraflexure in the walls, which, as will become clear in step 5, is useful for the calculation of the yield and design displacement profiles. When a coupled wall system responds in the fundamental mode of vibration, the coupling beams cause the upper portions of the walls to experience bending moments with a reverse sign to those at the base of the wall. The height of contraflexure can be found by taking the smallest positive root of Equation 3, or alternatively it can be determined directly from Figure 7. It should be noted, however, that these equations only apply to coupled walls with a uniform coupling beam strength distribution over the height of the building, as is adopted for this design. If non-uniform beam strengths were desired, the overturning resistance offered by the coupling beams above each level should be computed and subtracted from the total overturning demand to establish a wall bending moment profile, from which the contraflexure height could be established (for details, see the equivalent procedure for frame-wall structures in Sullivan et al. 2005, 2006). Furthermore, Equation 3 and Figure 7 assume that all coupling beams have yielded prior to development of the limit state being considered. This may not be the case for the serviceability limit state and further investigation is required to evaluate the design method at low intensities. For the ultimate limit state this assumption leads to reasonable estimates of the height of contraflexure.

The choice of making each coupling beam the same strength is again in line with the Paulay [2002] suggestion that the strength distribution is the designer's choice. Uniform coupling beams make for easier construction and it was shown by Fox [2013] that at the ultimate limit state a uniform strength distribution gives superior performance when compared to a strength distribution derived from elastic analysis typical of FBD. For the case study structure, the selected strength proportions lead to a height of contraflexure of $16.2 \mathrm{~m}\left(H_{C F} / H_{n}=0.68\right)$.

$$
\frac{1}{6}\left(\frac{H_{C F}}{H_{n}}\right)^{3}+\left(\frac{\beta}{3}-\frac{1}{2}\right)\left(\frac{H_{C F}}{H_{n}}\right)+\left(\frac{1}{3}-\frac{\beta}{6 n}-\frac{\beta}{3}\right)=0
$$

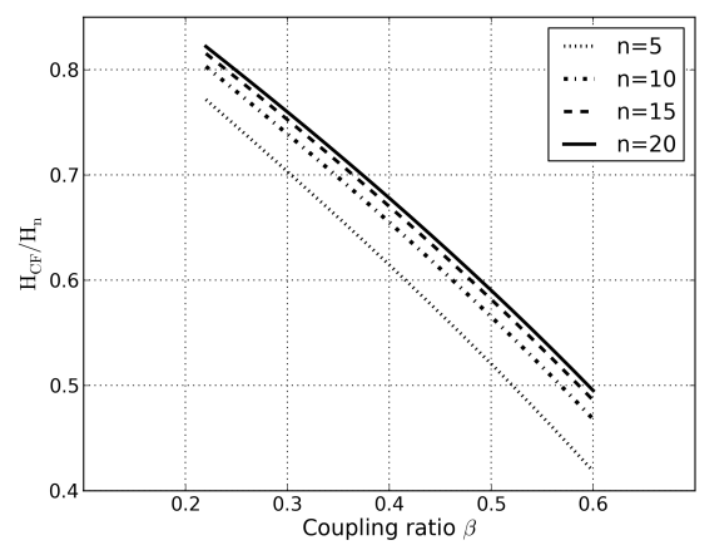

Figure 7: Contraflexure height for coupled wall with uniform coupling beam strength distribution.

Step 3-Determine the design plastic rotation at the base of the walls

Three potentially critical design limits must be considered in the DDBD of RC coupled walls; (i) a code inter-storey drift limit (2.5\% in accordance with NZS1170.5), (ii) coupling beam material strain limits, and (iii) wall material strain limits. These three different limits will be controlled by computing an allowable base plastic rotation of the RC walls. This will prove convenient for later calculation of the design displacement profile in step 5 .

To determine the allowable plastic rotation, it is first necessary to obtain rotation and curvature limits for the coupling beams and walls respectively, based on the material strain limits. For the coupling beams the force-displacement relationship can be defined by Equations 4 to 7 . As coupling beams are typically subjected to large deformation demands relative to the walls, it is assumed that all coupling beams will have yielded at the ultimate limit state. Note that Equations 3 and 4 are adapted from Paulay [2002] and Equations 5 and 6 are taken from Fox [2013]. 


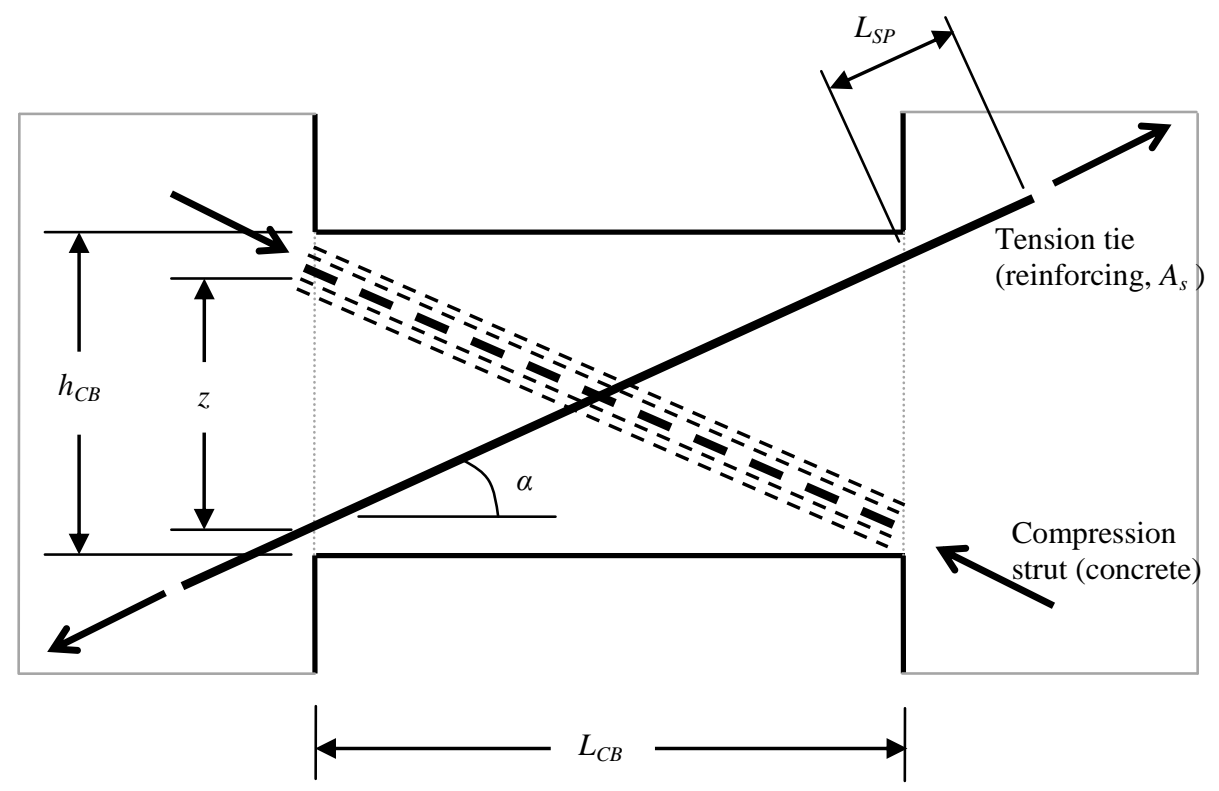

Figure 8: Geometry and mechanics of a diagonally reinforced coupling beam.

The basis of each equation used to define the coupling beam force-displacement relationship is explained with reference to Figure 8. Equation 4 gives the shear force in the coupling beam at yield and assumes that the diagonal reinforcing in one direction is at yield in tension while in the opposite diagonal there is an equal compression force (required to satisfy equilibrium). The diagonal forces are then related to the beam shear force through consideration of the inclination angle of the diagonal reinforcing, $\alpha$. Equation 5 gives the coupling beam chord rotation at yield, where chord rotation is defined as the angle between the tangent to the member axis at the end of the member and the chord connecting the two member ends. It assumes that the reinforcement yields over its full length, taken as the diagonal length between supports $\left(L_{C B} / \cos \alpha\right)$ plus an allowance for strain penetration $\left(2 L_{S P}\right)$. Multiplying this length by the yield strain gives the elongation of the diagonal reinforcement at yield. The compression diagonal is assumed to deform $30 \%$ of the tension diagonal deformation and hence the factor of 1.3 is obtained. The vertical deformation is obtained through division by $2 \sin \alpha$ and then the chord rotation is obtained through subsequent division by $L_{C B}$. Equation 6 gives the coupling beam shear at the design limit state. It is of a similar form to Equation 4, however, instead of using the reinforcing yield stress, $f_{y}$, it uses the stress corresponding to the limit state strain, $f_{s, l s}$, thus accounting for strain hardening. Equation 6 differs further from Equation 4 by accounting for the deformed geometry of the coupling beam, which can have a significant effect at the ultimate limit state. Equation 7 gives the coupling beam chord rotation at the design limit state and is formulated by assuming that the shortening of the compression chord is negligible. Although this appears contradictory to Equation 5, it is reasonable given that beyond yield the compression strains remain relatively constant. At the ultimate limit state the contribution of compression strains to the overall coupling beam deformation are negligible relative to the much larger tension strains.

$$
\begin{aligned}
& V_{C B, y}=2 \sin \alpha \cdot f_{y} A_{s, C B} \\
& \theta_{C B, y}=\frac{1.3\left(L_{C B} / \cos \alpha+2 L_{S P}\right) \varepsilon_{y}}{2 L_{C B} \sin \alpha}
\end{aligned}
$$

$$
\begin{aligned}
& V_{C B, l s}=\frac{2 \sin \alpha}{1+\varepsilon_{s, l s}\left(1+2 L_{S P} \sin \alpha / z\right)} f_{s, l s} A_{s, C B} \\
& \theta_{C B, l s}=\frac{\varepsilon_{s, l s}\left(L_{C B} / \cos \alpha+2 L_{S P}\right)}{2 L_{C B} \sin \alpha}
\end{aligned}
$$

For this example, the reinforcing material strain limit for the coupling beams is taken as $4 \%$, which when applied in Equation 7 gives a limit state rotation of $\theta_{C B, l s}=0.0741 \mathrm{rad}$. Note that in this research the strain penetration of the coupling beam reinforcing into the walls has been neglected for both the design and non-linear time-history verification stages. This was done in order to simplify the modelling approach (described in Section 5) and as it has been neglected for both design and analysis, it does not affect the results in terms of assessing the design method. The effect of strain penetration is to increase both the yield and limit state rotations and thus reduce the stiffness of the coupling beams. As such, in practice it would be recommended that the effect of strainpenetration be accounted for. At this stage it should also be noted that for DDBD low estimates of the expected material strengths should be used in design rather than lower bound characteristic values as used in NZS3101 [2006]. In accordance with Priestley et al. [1996] for lower bound characteristic strengths of $f^{\prime}{ }_{c}$ and $f_{y}$, low estimates of expected material strengths can be taken as $f_{c e}^{\prime}=1.3 f^{\prime} c$ and $f_{y e}=1.1 f_{y}$ for concrete and reinforcing respectively.

For the wall material strain limits, the corresponding limit state curvature for the base plastic hinge rotation is found from Equation 8, which is taken from Priestley et al. [2007]. A reinforcing steel material strain limit of $6 \%$ is used (it can be easily shown that concrete material strain limits will not govern in this case), which gives a limit state curvature of $0.0150 \mathrm{~m}^{-1}$. The yield curvature must also be determined. Using Equation 9 [Priestley et al., 2007] with expected material strengths, this is found to be $0.00138 \mathrm{~m}^{-1}$. It should be noted that the yield and limit state curvatures are rather insensitive to variations in reinforcing ratio and axial load ratio. This has been demonstrated by Priestley et al. [2007] in the ranges of $0-2 \%$ and $0-15 \%$ for reinforcing ratio and axial load ratio respectively. 


$$
\begin{aligned}
& \phi_{w, l s}=\frac{1.2 \varepsilon_{s, l s}}{L_{w}} \\
& \phi_{w, y}=\frac{2 \varepsilon_{y}}{L_{w}}
\end{aligned}
$$

The design plastic rotation, $\theta_{p C W}$, can be found using Equation 10. The first line of Equation 10 considers the code specified drift limit, while the second and third lines consider the coupling beam and wall material strain limits respectively. For the case study structure it is found that the coupling beam material strain limits govern the design plastic rotation, which is found to be 0.0136 radians. The corresponding inter-storey drift is $2.48 \%$; just under the code drift limit.

$$
\theta_{p C W}=\min \left\{\begin{array}{c}
\theta_{c}-\frac{\phi_{w, y} H_{C F}}{2} \\
\frac{\theta_{C B, l s}}{1+L_{w} / L_{C B}}-\frac{\phi_{w, y} H_{C F}}{2} \\
\left(\phi_{w, l s}-\phi_{w, y}\right) L_{p}
\end{array}\right\}
$$

\section{Step 4- Identify a higher mode reduction factor}

The effects of higher modes on the deformations of the structure are accounted for using the factors presented in Figure 9. The two different lines are set for buildings with plastic hinges up their height (frames) and plastic hinges at the base only (walls). As coupled walls have plastic hinges up their height, but also exhibit wall like behaviour, it was assumed that the most appropriate way to apply the higher mode factor was by taking an average weighted on the coupling ratio. In this case for the seven storey building with $\beta=0.35$ the higher mode factor is $\omega_{\theta}=0.35 \times 0.985+(1-0.35) \times 1.0=0.995$. This is not particularly significant, as would be expected for a structure of this height, for which higher modes do not make a particularly large contribution. However, for taller structures the effects of higher modes can be significant and should be accounted for.

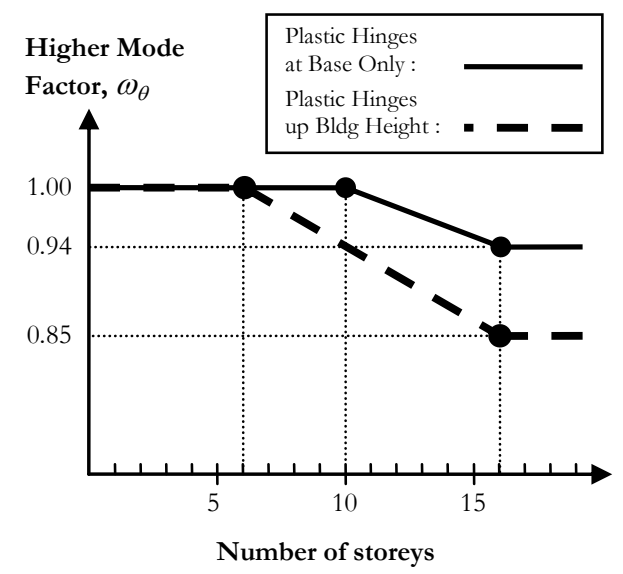

Figure 9: Higher mode factors from DBD12 [Sullivan et al., 2012].

\section{Step 5-Calculate the yield and design displacement profiles}

For the design of coupled walls in DDBD the yield displacement profile is defined as that at which the walls reach their nominal yield curvature and it should be noted that at this point it is assumed that all coupling beams have already yielded. To calculate the displacement profile at yield, the approach for frame-wall structures by Sullivan et al. [2005, 2006] is adopted and it is assumed that the curvature of the walls can be approximated with the bilinear diagram as shown in Figure 10. The linear curvature profile implicitly makes allowance for some shear deformation and tension shift effects (see Priestley et al., 2007) and was shown to work well for RC frame-wall structures by Sullivan et al. [2004]. Above the height of contraflexure it is assumed, for simplicity, that the wall curvatures are zero. This latter assumption can be shown to have little effect on the displacement profile.

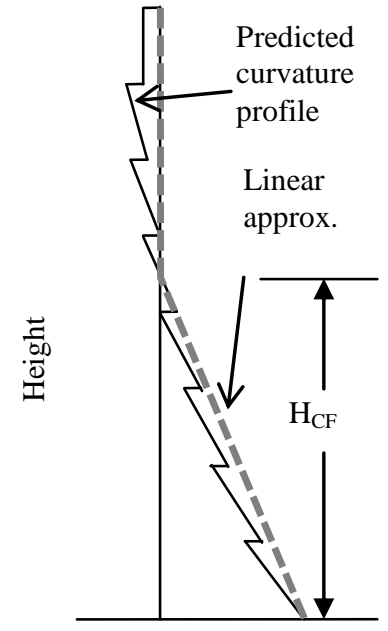

Curvature

Figure 10: Linear approximation to wall curvature diagram for calculating yield displacement profile.

Based on the simplified curvature diagram of Figure 10, Equations 11 and 12 can be used to calculate the yield displacement at each floor up the height of the structure.

for $h_{i} \leq H_{C F}$ :

$$
\Delta_{i y}=\phi_{w, y}\left(\frac{h_{i}^{2}}{2}-\frac{h_{i}^{3}}{6 H_{C F}}\right)
$$

for $h_{i}>H_{C F}$ :

$$
\Delta_{i y}=\phi_{w, y}\left(\frac{H_{C F} h_{i}}{2}-\frac{H_{C F}^{2}}{6}\right)
$$

Having determined the yield displacement at each floor level, the corresponding design displacement can be found by adding on the additional displacement due to the allowable plastic rotation at the base of the walls (Equation 10) and then reducing this allowable first mode displacement profile by the higher mode reduction factor, as per Equation 13.

$$
\Delta_{i . l s}=\left(\Delta_{i y}+\theta_{p C W} h_{i}\right) \omega_{\theta}
$$

\section{Step 6-Calculate properties of SDOF representation}

At this stage it is possible to determine the effective height, $H_{e}$, yield displacement, $\Delta_{y}$, design displacement, $\Delta_{d}$, and effective mass, $\mathrm{m}_{e}$, of the equivalent SDOF representation. 
This is done through Equations 14 to 17 from Priestley et al. [2007].

$$
\begin{aligned}
& H_{e}=\frac{\sum_{i=1}^{n}\left(m_{i} \Delta_{i, l s} h_{i}\right)}{\sum_{i=1}^{n}\left(m_{i} \Delta_{i, l s}\right)} \\
& \Delta_{y}=\frac{\sum_{i=1}^{n}\left(m_{i} \Delta_{i, y}^{2}\right)}{\sum_{i=1}^{n}\left(m_{i} \Delta_{i, y}\right)} \\
& \Delta_{d}=\frac{\sum_{i=1}^{n}\left(m_{i} \Delta_{i, l s}^{2}\right)}{\sum_{i=1}^{n}\left(m_{i} \Delta_{i, l s}\right)} \\
& m_{e}=\frac{\sum_{i=1}^{n}\left(m_{i} \Delta_{i, l s}\right)}{\Delta_{d}}
\end{aligned}
$$

For the case study structure one obtains $H_{e}=17.4 \mathrm{~m}$, $\Delta_{y}=0.134 \mathrm{~m}, \Delta_{d}=0.371 \mathrm{~m}$ and $m_{e}=1690 \mathrm{t}$. Note that the effective mass has been computed considering only half of the total building mass.

\section{Step 7- Calculate wall and coupling beam ductility demands}

For seismic design we aim to characterise a ductile structure with a single displacement ductility factor. In the case of coupled walls, because the ductility demands on the coupling beams and walls can vary significantly, it is preferable to calculate separate ductility factors for each. For the walls, the ductility demand is simply the design displacement of the SDOF representation divided by the yield displacement as per Equation 18.

$$
\mu_{w}=\frac{\Delta_{d}}{\Delta_{y}}
$$

For the coupling beams the ductility demand on each beam will vary up the height of the structure. An appropriate simplification for design is to calculate the average coupling beam ductility demand, which can be found using Equation 19. One will recall that a check of the maximum allowable coupling beam ductility demand has already been done through Equation 10.

$$
\mu_{C B}=\frac{\Delta_{n}\left(1+L_{w} / L_{C B}\right)}{H_{n} \theta_{C B, y}}
$$

where $\theta_{C B, y}$ comes from Equation 5 .

For the case study structure, application of Equations 18 and 19 give $\mu_{w}=2.76$ and $\mu_{C B}=10.2$.

Step 8- Calculation of system EVD and displacement reduction factor

To determine the system EVD ratio, it is first necessary to determine the EVD ratios for the walls and coupling beams separately. For the walls Equation 20 is used, based on a Takeda thin hysteresis rule, and for the coupling beams
Equation 21 is adopted, assuming a Takeda fat hysteresis rule (refer Grant et al., 2005, for definition of 'Takeda thin' and 'Takeda fat').

$$
\begin{aligned}
& \xi_{w}=0.05+0.444\left(\frac{\mu_{w}-1}{\mu_{w} \pi}\right) \\
& \xi_{C B}=0.05+0.565\left(\frac{\mu_{C B}-1}{\mu_{C B} \pi}\right)
\end{aligned}
$$

To obtain the system EVD, the separate EVD ratios for walls and coupling beams are combined by weighting the two different EVD ratios based on their mechanism's contribution to resisting the overturning moment.

$$
\xi_{s y s}=(1-\beta) \xi_{w}+\beta \xi_{C B}
$$

The equivalent viscous damping ratios for the case study example are $\xi_{w}=0.140, \quad \xi_{C B}=0.212$ and $\xi_{s y s}=0.165$. The displacement reduction factor is found using Equation 23, which for an EVD ratio of 0.165 gives a reduction factor of 0.614 . The reduction factor is used to compute the spectrum for the desired EVD ratio from the 5\% damped displacement spectrum as shown in Figure 11.

$$
R=\left(\frac{0.07}{0.02+\xi_{\text {sys }}}\right)^{0.5}
$$

Equations 20 to 23 have all been obtained from Priestley et al. [2007]. Note that for reasons given by Pennucci et al. [2011], Equation 23 should be used with the EVD values given by Equations 20 and 21 even if the local hazard is characterised by ground motions that are expected to scale differently with damping.

\section{Step 9- Calculate base shear}

Entering the reduced (highly damped) displacement spectrum with the design displacement, the effective period is found, as per Figure 11. For the case study structure the design displacement of $0.371 \mathrm{~m}$ gives an effective period of $T_{e}=2.84 \mathrm{~s}$.

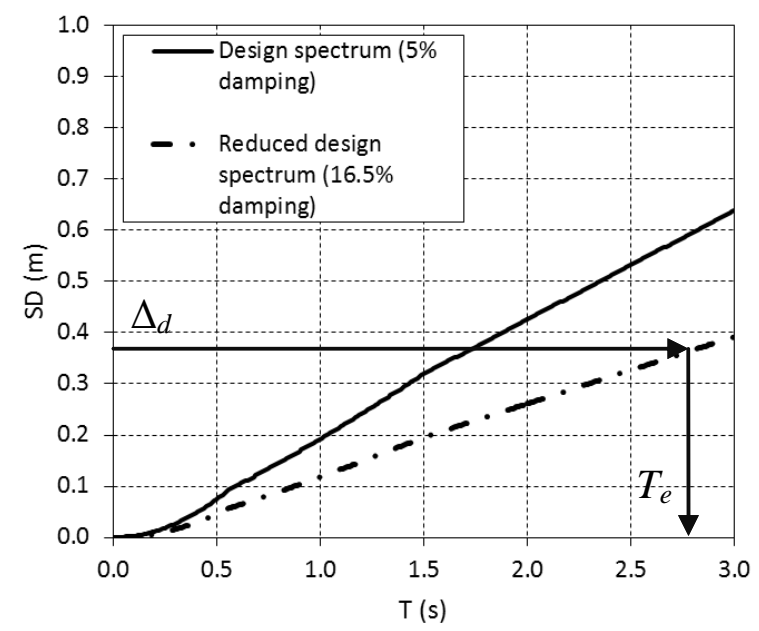

Figure 11: Reduced displacement spectrum used to obtain effective period. 
Once the effective period is obtained it can be used to find the effective stiffness (Equation 24) and in turn the base shear can be calculated (Equation 25). For the case study structure the design base shear is found to be $3068 \mathrm{kN}$.

$$
\begin{gathered}
K_{e}=\frac{4 \pi^{2} m_{e}}{T_{e}^{2}} \\
V_{b}=K_{e} \Delta_{d}
\end{gathered}
$$

A P-delta check is then carried out by determining the value of $m_{e} g / K_{e} H_{e}$, which in this case is found to be 0.115 and is above the limit of 0.05 given in DBD12 [Sullivan et al., 2012], therefore, P-delta effects must be accounted for. To account for P-delta effects the base shear is increased by adding on the shear force found from Equation 26.

$$
V_{P-\Delta}=C \frac{\sum_{i=1}^{n} P_{i} \Delta_{i}}{H_{e}}
$$

For the case study structure the coefficient $C$ is taken as 0.5 as recommended by Priestley et al. [2007] for concrete structures. This gives a P-delta shear force of $176 \mathrm{kN}$ and a total base shear of $3245 \mathrm{kN}$. The estimated increase in base shear due to P-delta effects corresponds to $5.4 \%$.

Step 10-Determine required strength of coupling beams and walls

The required strength of the coupling beams and walls is now determined based on the strength distribution chosen at the start of the design. The coupling beam shear forces and wall moments can be found from Equations 27 and 28 respectively.

$$
\begin{gathered}
V_{C B}=\beta \frac{V_{b} H_{e}}{n\left(L_{w}+L_{C B}\right)} \\
M_{\text {wall }}=(1-\beta) \frac{V_{b} H_{e}}{2}
\end{gathered}
$$

For the case study structure the required shear strength of the coupling beams is $472 \mathrm{kN}$ and the required flexural strength of each wall is $18.4 \mathrm{MNm}$. The area of diagonal reinforcing required for the coupling beams is found from Equation 6 and the quantity of flexural reinforcing in the walls can be found from moment-curvature analysis. Note that the flexural resistance of each wall will vary depending on the axial load on the wall, with the latter changing due to the shear forces transferred by the coupling beams. However, as long as the axial load on the walls is not near the balance point, it is sufficiently accurate to consider the average axial loads on the walls (i.e. gravity load only) when determining the moment capacity to be provided, as explained by Priestley et al. [2007].

At this point the design procedure would continue with capacity design. However, as the focus in this case is on the performance of the structure in terms of deformations/displacements the capacity design portion is not reported here. Interested readers may refer to Fox et al. [2014] for discussion of capacity design aspects specific to coupled walls. The key outputs from the design are provided in Table 2.
Table 2. Key design outputs from DDBD.

\begin{tabular}{|c|c|}
\hline$T_{l}(\mathrm{~s})$ & 1.47 \\
\hline Max. drift $(\%)$ & 2.47 \\
\hline$V_{b}(\mathrm{kN})$ & 3245 \\
\hline$\rho_{w}(\%)$ & 1.51 \\
\hline$N_{c} / f^{\prime}{ }^{\prime} A_{g}$ & 0.119 \\
\hline$N_{t} / f_{y} A_{s}$ & 0.155 \\
\hline$A_{s, C B}\left(\mathrm{~mm}^{2}\right)$ & 1350 \\
\hline
\end{tabular}

\section{FORCE-BASED DESIGN}

Design of the same case study structure is carried out using FBD in accordance with NZS1170.5:2004 and NZS3101:2006. As the procedure is generally well known amongst structural engineers involved in seismic design, it will not be described in detail, but rather some of the important points specific to this case study will be discussed.

The first key point in FBD is the choice of ductility factor, which is then used to determine the force reduction factor, $k_{\mu}$. From NZS3101 an upper limit of $\mu_{\text {sys }}=6$ is allowed for coupled walls. However, this is dependent on both the aspect ratio of the walls and the coupling ratio, $\beta$ (given the notation $A$ in NZS3101). The relationship between ductility factor and coupling ratio is such that for a higher coupling ratio the allowable ductility factor increases. The drawback of this approach is that in FBD the coupling ratio is not known $a$ priori and so to avoid an iterative approach a ductility factor of five was conservatively selected here, which is allowed for any coupling ratio (including a coupling ratio of zero, which is effectively a pair of cantilever walls). The ductility factor is also limited by how squat the walls are, such that for walls that have an aspect ratio less than three, a lower ductility factor must be used. Interestingly there is no restriction on ductility factor for a high aspect ratio. As explained by Priestley et al. [2007], as a wall becomes more slender the maximum allowable ductility demand begins to reduce to unity.

For the ductility factor of five the corresponding structural performance factor is $S_{P}=0.7$. The structural performance factor is then used to further reduce the base shear for which the structure must be designed. This gives the design response spectrum defined by Equation 29.

$$
C_{d}(T)=\frac{C(T) S_{p}}{k_{\mu}}
$$

According to the Canterbury Earthquakes Royal Commission Report: Volume 1 [2012] the structural performance factor "was introduced to allow for a number of factors that are not easily quantified and are not directly accounted for in the design process." In the context of applying a design method such that it can achieve a certain performance level in terms of displacements and deformations, the inclusion of the structural performance factor does not seem appropriate. However, in keeping with the FBD code approach the factor of 0.7 is used.

The second point of interest is the stiffness of the elements to be used in modelling the structure. In the case of the walls it is fairly straight forward. From Part 2 of NZS3101 the appropriate ratio of effective moment of inertia to gross moment of inertia $\left(I_{e} / I_{g}\right)$ is determined based on the axial load ratio and reinforcing yield stress. In this case a value of $I_{e} / I_{g}=0.30$ is obtained. For the coupling beams the ratio NZS3101 recommends is $I_{e} / I_{g}=0.6$. However, NZS3101 also 
notes that "diagonally reinforced coupling beams deform predominantly in shear" and for this reason the shear stiffness needs to be accurately determined. This is done by calculating the shear area $A_{\text {Shear }}$ in accordance with NZS3101 equations Eq.C6-9 to Eq.C6-11(b), which are reproduced here for convenience.

$$
\begin{aligned}
& V_{d}=2 A_{d} f_{y} \sin \alpha \\
& \delta_{y}=\left[\frac{L}{\cos \alpha}+\frac{f_{y} d_{b}}{15}\right] \frac{f_{y}}{E_{s}} \\
& \delta_{v}=\frac{1.2 \delta_{y}}{2 \sin \alpha} \\
& A_{\text {shear }}=\frac{V_{y}}{G L \delta_{y}}
\end{aligned}
$$

This approach causes some difficulties; however, before further discussion it is necessary to highlight a number of existing errors in this section of the standard. While they are only minor errors, which in all likelihood would be identified by competent engineers, they are worth identifying here for completeness. They are listed as follows:

1) $\delta_{y}$ in Eq. C6-10 is incorrectly quoted as being the shear deformation of the coupling beam at yield. Considering the original definition provided by Paulay [2002a] it would instead appear to be the axial elongation of the diagonal reinforcing in tension at yield (including an allowance for strain penetration).

2) Eq. C6-11(b) is written incorrectly, as previously pointed out by Fenwick \& Cook [2010]. The length of the coupling beam $L$, should be part of the numerator as shown in Equation 30, not part of the denominator as is currently written in NZS3101.

3) In Eq. C6-11(b), $\delta_{y}$ is used to calculate the shear area. Instead of $\delta_{y}$ it should in fact be shear deformation at yield $\delta_{v}$ from Eq. C6-11(a). This is obvious given that Eq. C611(b) (correctly written as Equation 30) is the equation for the shear stiffness of a member rearranged to solve for $A_{\text {shear }}$.

$$
A_{\text {shear }}=\frac{V_{y} L}{G \delta_{v}}
$$

Inspection of Equation 30 immediately highlights the problem in determining the shear area, that is, the yield shear force $V_{y}$, which is a function of the area of reinforcing provided, is not known at the start of the design, i.e. the stiffness cannot be estimated before the strength is known. It has been assumed in this work that the appropriate procedure to determine the shear area is as follows:

1) Assume a reasonable first estimate of the shear area.

2) Carry out an elastic analysis and determine the shear force in each coupling beam.

3) Use the coupling beam shear forces from the analysis in Equation 30 to obtain a better estimate of the shear area of each coupling beam.

4) Repeat until convergence is obtained.
Obviously this is frustrating from a designer's point of view as the design process becomes iterative. Furthermore, it is likely to result in a highly uneven distribution of reinforcing between the coupling beams. The uneven distribution of reinforcing can be explained by first considering the displaced shape of a coupled wall deforming elastically. At the base of the structure the slope of the walls is zero. The slope then increases up to its maximum at the height of contraflexure (refer 10). Above the height of contraflexure the slope of the walls starts to reduce again. The deformation demand on each coupling beam is approximately proportional to the corresponding wall slope and therefore the elastic analysis gives coupling beam deformation demands that are largest at the height of contraflexure and then decrease towards roof level and towards the foundation. Consider now the case where a designer assumes for a first iteration that all coupling beams have the same shear area (and therefore stiffness). When the elastic analysis is carried out, coupling beams towards the height of contraflexure will deform the most and therefore attract the highest shear forces. Consequently, for the next iteration the stiffness of the coupling beams near the height of contraflexure must be increased (in accordance with Equation 30) relative to those near roof level or the base of the structure. With each subsequent iteration this imbalance in strength and stiffness will be exacerbated. A further complication may occur in some structures that have very stiff walls. In these instances the displacement demand on some coupling beams (most likely the first floor coupling beam) may not exceed the yield displacement. Therefore, with each iteration the coupling beam shear force reduces towards zero.

This highly uneven distribution of reinforcing is illogical when the inelastic displaced shape of the coupled wall is considered. Once a mechanism forms (all coupling beams and the walls yield) the walls begin to rotate as rigid bodies. This evens out the coupling beam drift demands up the height of the structure, for which an even distribution of reinforcing makes more sense. Having said this, it should be acknowledged that some benefit from the NZS3101 approach may be gained at the serviceability limit state as the onset of yielding is delayed. Furthermore, the uneven distribution of reinforcing can be alleviated to some extent by making use of the allowance for redistribution between the coupling beams.

Incorporating the aforementioned approach to calculating the stiffness of the coupling beams, the modal response spectrum method was used to determine the base shear for the case study structure, which came out at $V_{b}=1410 \mathrm{kN}$, significantly less than what was determined using DDBD.

In accordance with NZS1170.5, P-delta effects were assessed and the maximum stability coefficient was found to be 0.252 . As this is greater than 0.1, P-delta effects cannot be neglected. Method B (see NZS1170.5 clause 6.5.4.2) was used to account for P-delta effects. The method can be summarised in the following steps:

1) Take a standalone column equal to the height of the structure, which is pinned at each floor level and then displaced laterally to match the displacements found from the equivalent static or modal response spectrum analysis (and scaled appropriately to account for inelastic response).

2) Apply the gravity load for each floor to the column and determine the lateral forces required at each level to maintain equilibrium (in the displaced shape).

3) Apply the set of lateral forces found in step 2 to the model of the structure and determine the additional design actions and displacements.

4) Determine the factor $\beta_{P-4}$, which is dependent on ductility, soil type and the first mode period of vibration. 
For the case study structure this is found to be 2 . Note that the sub-script $P-\Delta$, which is not include in NZS3101, has been added to avoid confusion with the $\beta$ used to denote coupling ratio.

5) Multiply the additional design actions found in step 3 by $\beta_{P-\Delta}$ and add them to the actions found in the equivalent static or modal response spectrum analysis.

6) Multiply the additional displacements found in step 3 by $\mu \beta_{P-\Delta}$ and add them to the displacements found in the equivalent static or modal response spectrum analysis.

This increased the base shear to $1683 \mathrm{kN}$ and increased the maximum storey drift by a factor of 1.25 . The key design outputs from the force-based design are provided in Table 3. Note that to reduce the number of different coupling beams, some redistribution has been allowed for. Furthermore, as the required quantity of reinforcing in the first floor coupling beam was so low, a minimum quantity of reinforcing of $0.50 \%$ has been provided.

Table 3. Key design outputs from FBD.

\begin{tabular}{|c|c|}
\hline$T_{l}(\mathrm{~s})$ & 1.48 \\
\hline Max. drift (\%) & 2.64 \\
\hline$V_{b}(\mathrm{kN})$ & 1683 \\
\hline$\rho_{w}(\%)$ & 0.684 \\
\hline$N_{c} / f^{\prime}{ }_{c} A_{g}$ & 0.129 \\
\hline$N_{t} / f_{y} A_{s}$ & 0.095 \\
\hline$A_{s, C B 7}\left(\mathrm{~mm}^{2}\right)$ & $1007(1065)^{*}$ \\
\hline$A_{s, C B 6}\left(\mathrm{~mm}^{2}\right)$ & $1556(1556)$ \\
\hline$A_{s, C B 5}\left(\mathrm{~mm}^{2}\right)$ & $2137(2031)$ \\
\hline$A_{s, C B 4}\left(\mathrm{~mm}^{2}\right)$ & $2137(2297)$ \\
\hline$A_{s, C B 3}\left(\mathrm{~mm}^{2}\right)$ & $2137(2084)$ \\
\hline$A_{s, C B 2}\left(\mathrm{~mm}^{2}\right)$ & $1007(950)$ \\
\hline$A_{s, C B 1}\left(\mathrm{~mm}^{2}\right)$ & $804(4)$ \\
\hline \multirow{2}{*}{$\begin{array}{c}\text { Bracketed values are of the exact quantities of } \\
\text { of reinforcing required from the analysis } \\
\text { rather than the actual amount provided. }\end{array}$}
\end{tabular}

The maximum storey drift is slightly above the code prescribed maximum of $2.5 \%$, and in practice one should increase the stiffness of the system in order to satisfy the drift limit. However, the design process was halted here because the allowance for P-delta effects was expected to be conservative (as will be shown in Section 7) and refining the FBD solution would not affect the aim of this paper, which is to investigate the ability of FBD and DBD procedures to control deformation demands.

To highlight the differences between DBD and FBD for coupled wall buildings, the performance of the case study building will be examined using non-linear time-history analyses as explained in the next section. However, before proceeding further with the case study comparison, it is worth identifying the important differences between the FBD method just described and the DDBD procedure presented in Section 3 for coupled RC walls:

1) In FBD the structural proportions are assumed to be irrelevant to the displacement ductility capacity (gauged through the ductility reduction factor) but will significantly affect capacity and inelastic displacement demands in DDBD.

2) Design base shear will be proportional to a change in seismic intensity for FBD but will be proportional to the square of a change in intensity in DDBD (as explained in Priestley et al., 2007).

3) The choice of material properties will not affect the predicted displacement demands according to FBD but will affect those in DDBD (affecting the yield deformations, as shown Equations 11 and 12, and the ultimate deformation capacity as shown in Equation 10 and 13 , leading to a change in ductility and equivalent viscous damping with a subsequent change in predicted inelastic displacement).

4) If structural dimensions are held constant and uniform coupling beam sizes are assumed, then an increase in coupling ratio will lead to lower DDBD base shear until the coupling ratio becomes so large that significant net tension forces in the walls becomes an issue (or the wall curvature limits become critical). In FBD the structural dimensions will dictate the coupling ratio and so the designer does not have the same freedom to optimise the design as in DDBD.

Considering the points made above, it becomes clear that the single case study structure examined in this work will not be able to quantify the full extent to which FBD and DDBD differ. However, the sections that follow will present some interesting differences in performance that should help engineers gain more insight into the critical design factors for coupled RC wall systems.

\section{MODELLING AND ANALYSIS}

To assess the two design methods each design solution was modelled and analysed using non-linear time-history analyses in SeismoStruct V6 [Seismosoft, 2012]. The coupled walls were modelled using distributed plasticity fibre-section elements. This approach was considered superior to a lumped plasticity approach for the following reasons:

1) Non-linearity is defined at the material level. Therefore it is only necessary to define the section geometry and material stress-strain relationships. In this study the Menegotto-Pinto [1973] model was used for the reinforcing and the Mander et al. [1988] model for the concrete (both confined and unconfined).

2) Moment-axial load interaction is accounted for implicitly by the fibre-sections. It is therefore not necessary to incorporate an explicit moment-axial load interaction rule into the model. Note that moment-axial load interaction is particularly important in the case of coupled walls, where the coupling beams generate significant axial load variations in the walls.

3) Axial elongation due to flexure is captured. For typical RC sections under flexural loading the neutral axis position shifts towards the compressive edge of the section, rather than being at the section centroid. Therefore, the length of an element measured at the centroid of the section will elongate due to flexure. This behaviour is important to capture when modelling coupled walls as it will affect the deformation demands on the coupling beams. Furthermore, the cumulative effect of residuals strains during cyclic loading can be captured if they are accounted for in the material models (as they are in this work).

When distributed plasticity elements are used, it is necessary to consider the mathematical formulation of the elements. Like a number of other software packages, SeismoStruct offers both displacement-based and force-based formulations. Force-based formulations tend to give very high inelastic curvature concentrations at the base of the walls and so displacement-based elements were used. The formulation of 
these beam elements is based on the assumption of a linear curvature profile along the length of the element, i.e., the same profile which is also assumed over the height of a plastic hinge. To obtain similar strain predictions with such beam element models as one would obtain from plastic hinge models (which have been calibrated against experimental data), the element length at the base should be set (by the user) equal to the plastic hinge length. For a more detailed discussion on this modelling choice, readers are referred to Yazgan \& Dazio [2010]. The plastic hinge length can be calculated using Equation 31 from DBD12 [Sullivan et al., 2012].

$$
L_{P}=k H_{n}+0.1 L_{w}+L_{S P}
$$

where $k=0.15\left(f_{u} / f_{y}-1\right) \leq 0.06$, and $L_{S P}=0.022 f_{y e} d_{b l}$ (in units of Newtons and millimetres). For the case study structure the plastic hinge length was calculated as $1.37 \mathrm{~m}$.

The mesh discretisation up the remaining height of the building corresponds to one element per wall per storey. A screen shot of one of the models is shown in Figure 12. Note the additional flexible frames on each side to model P-delta effects.

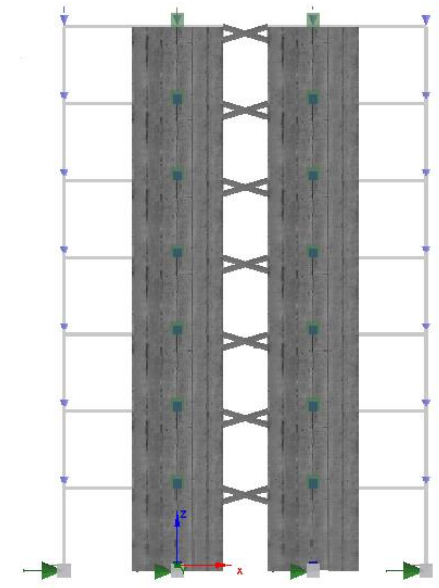

Figure 12: SeismoStruct screenshot of model used for NTHA.

The coupling beams were modelled as a pair of diagonal trusses using fibre-section truss elements. These behave in a similar manner to the fibre-section elements used to model the walls, but resist axial forces only and not bending moments or shear. To verify this modelling approach, an isolated coupling beam tested by Paulay \& Binney [1974] was modelled and pushed through the same displacement regime as the experimentally tested beam. The results are compared in Figure 13 and it can be seen that the modelling approach accurately captures the shear-rotation response of the experimental test. Similar results were obtained for a number of additional coupling beams (see Fox, 2013), suggesting that the modelling approach adopted here is reasonable.

It is well known that conventional floor slabs interact with beams and can increase their strength and this should be accounted for during the design process (in particular capacity design considerations). However, in this research the effects of the floor slab have not been included owing to uncertainties associated with accurate modelling of the floor slab. As the interaction with the floor slab is neglected in both design and analysis, this approach does not affect the research objective of providing a comparison between the DDBD and FBD design methods. However, coupling beam to floor slab interaction appears to be a particularly important area for future research.
The manner in which viscous damping is incorporated into NTHA can have a significant effect on the results. Traditionally Rayleigh damping is used in NTHA as the incorporation of both mass and stiffness proportional components allows for a relatively constant level of damping across a number of modes.

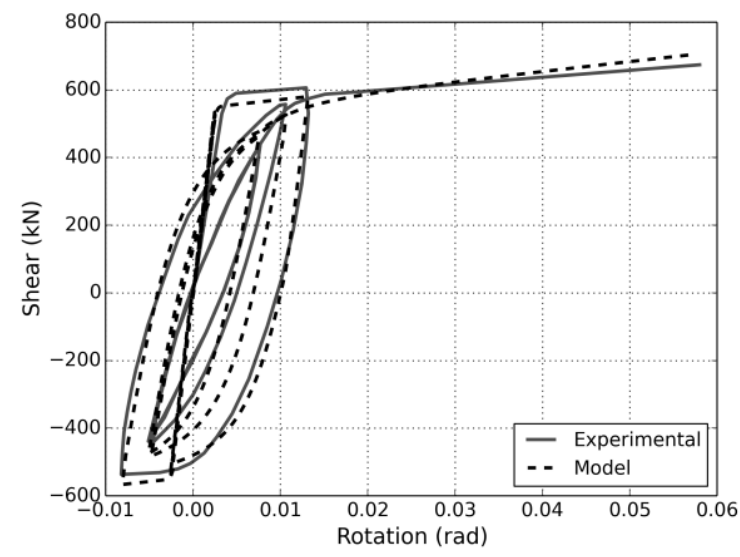

Figure 13: Comparison of shear-rotation response of coupling beams as observed by Paulay \& Binney [1974] compared with numerical results obtained using fibresection truss elements.

The downside of Rayleigh damping is that as the structure goes into the inelastic range, the effective period of the structure lengthens and therefore the fraction of critical damping increases. This can be alleviated to some extent by using the tangent stiffness matrix rather than initial stiffness, but the same cannot be done for the mass proportional component (without artificially reducing the damping). Considering these drawbacks, tangent stiffness proportional damping has been used based on the recommendations of Grant et al. [2005] and Petrini et al. [2008]. While this option is preferred, it still has some significant drawbacks. Firstly, the fraction of critical damping cannot be quasi-constant across the significant modes, but instead increases linearly with period. Secondly, stiffness proportional damping (both tangent and initial) can induce spurious axial forces in members as highlighted by Correia et al. [2012].

Using the tangent stiffness proportional damping approach, $2 \%$ of critical damping was applied at the period corresponding to the fundamental mode of vibration. The value of $2 \%$ is much lower than the conventional $5 \%$ used for reinforced concrete structures as some of the damping is accounted for through the use of a fibre-element model, as explained by Petrini et al. [2008]. Furthermore, the damping in the fundamental mode must be kept sufficiently low such that the higher modes are not excessively damped. Even with only $2 \%$ damping specified in the fundamental mode this results in approximately $8 \%$ at the second mode of vibration. Although this is higher than typically assumed for design, it will not significantly affect the results as the higher mode contribution to the total displacement/drift response is very low for the structure at hand.

The fibre-section elements used to model the walls are rigid in shear and therefore, additional spring elements were included at each floor level to account for shear deformations. RC sections responding in the inelastic range for flexure also exhibit non-linear response in terms of shear. To capture this behaviour requires advanced modelling solutions; however, Beyer et al. [2014] have shown that reasonable results can still be obtained using linear shear stiffness. The stiffness of the shear springs was determined using Equation 32 from Beyer $e t$ al. [2011]. The equation is semi-empirical and accounts for experimental evidence showing that the ratio of shear to 
flexural deformations in capacity designed walls remains relatively constant [Dazio et al., 2009]. They values for curvature, $\phi$, and mean axial strain, $\varepsilon_{m}$, used in Equation 32, were taken for when the walls were at half the expected maximum curvature ductility.

$$
\frac{\Delta_{s}}{\Delta_{f}}=1.5 \frac{\varepsilon_{m}}{\phi \tan \beta_{c r}} \frac{1}{H_{n}}
$$

Knowing the shear force in the wall, Equation 32 can be rearranged to give the shear stiffness, $k_{s}$, of an equivalent cantilever subject to an applied point load $V$. Taking the maximum crack inclination, $\beta_{c r}$, as $45^{\circ}$ then gives Equation 33

$$
k_{s}=\frac{V}{\Delta_{s}}=\frac{\phi V H_{n}}{1.5 \varepsilon_{m} \Delta_{f}}
$$

The accelerograms used in the NTHAs are taken from Maley et al. [2013], which have been selected and scaled so that they match the spectrum on average across the full range of periods of interest. The pseudo-acceleration and displacement response spectra are shown in Figure 4 and Figure 5 respectively.

In Section 3 it was mentioned that the DDBD procedure used low estimates of expected material strengths while the FBD procedure used lower bound characteristic material strengths. In the NTHA, expected material strengths were used for both the DDBD and FBD models to allow for a fair comparison between the two approaches. In addition to the discrepancy in material strengths, it should also be noted that the FBD approach in accordance with NZS3101 requires the use of strength reduction factors when computing the strength of structural elements. The net result of the material strength discrepancy and the use of strength reduction factors is that the maximum base shear developed in the FBD model is significant larger than what was calculated during design. This is demonstrated in Figure 14, which shows the results of pushover analyses for each model when subjected to an inverse triangular force pattern. This discrepancy in model versus design base shear should be taken into account when interpreting results in the following section.

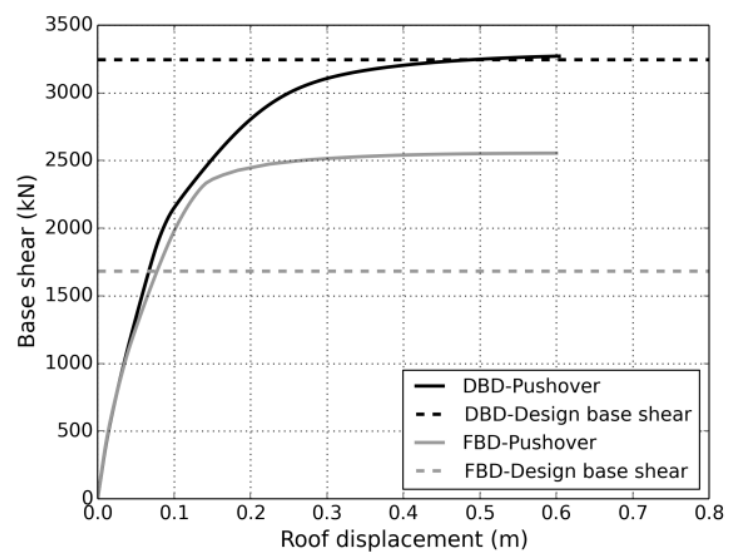

Figure 14: Comparison of pushover curves with design base shear for the two different numerical models designed using DDBD and FBD.

\section{ANALYSIS RESULTS FOR COMPARISON OF THE DESIGN METHODS}

In this section the accuracy of the two design methods is gauged by comparison with the results of the NTHAs. Specifically, the observed maximum inter-storey drift up the height of the structure will be compared with the drift values predicted during design. It will be recalled from Section 3 that materials strains at the base of the wall and in the coupling beams can both be related to the inter-storey drift (Equation 10) and therefore from a design point of view the only parameter that needs to be considered to assess the performance of the structure, in terms of it reaching a given limit state is the inter-storey drift. From an analysis point of view this is not quite the case as the influence of higher modes means that the drift at the height of contraflexure cannot be directly related to the material strains at the base of the walls. Furthermore, the coupling beam material strains are also affected by the differential axial elongation of the walls, as stated in Section 5, and therefore cannot be directly related to inter-storey drift without some minor loss of accuracy. Despite these drawbacks, inter-storey drift is still the most useful parameter for comparison between design and analysis and indicating the success (or failure) of the design method.

The design drift profile from DDBD is shown in Figure 15 alongside the maximum storey drifts for each accelerogram individually and the mean maximum storey drift. It can be seen that the mean NTHA result matches the design drift profile fairly closely up the whole height of the building, with the mean NTHA drifts being slightly less than the design drifts. Figure 16 shows the same results for the case study structure designed using FBD.

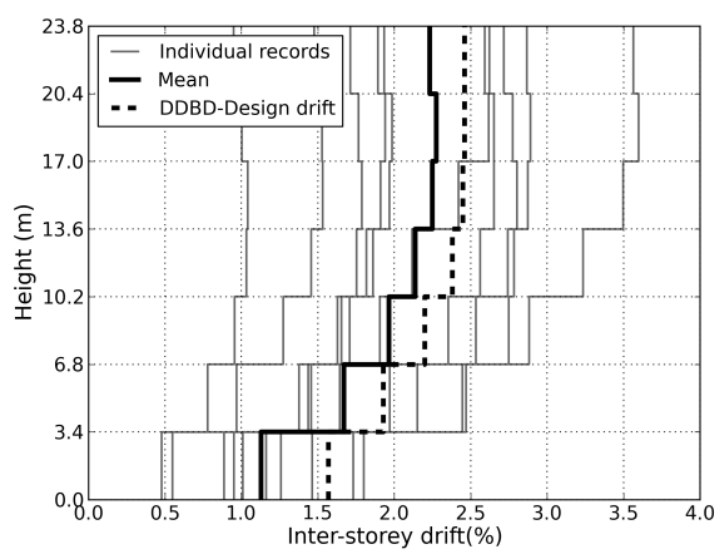

Figure 15: Comparison of design and NTHA inter-storey drifts for DDBD building.

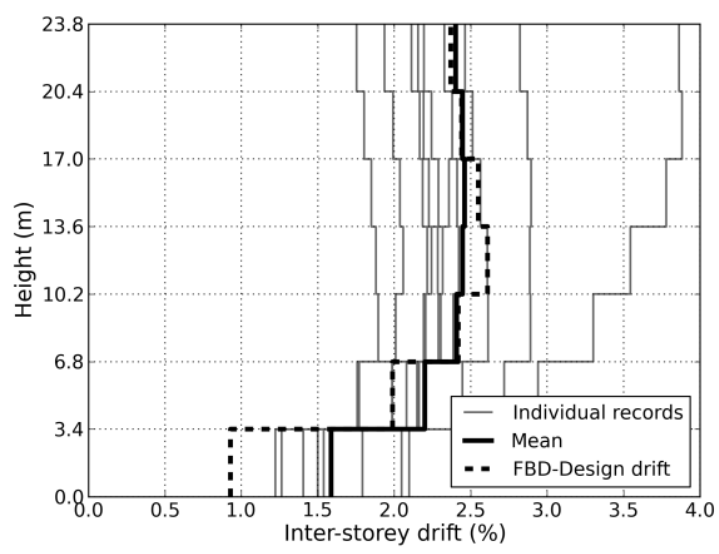

Figure 16: Comparison of design and NTHA inter-storey drifts for FBD building. 
Table 4 shows a comparison of the maximum inter-storey drifts for both design methods and analyses, along with the associated errors. The maximum mean inter-storey drift from the NTHA results matches fairly closely the maximum interstorey drift predicted from the FBD, again with the NTHA inter-storey drifts being slightly smaller. Although this appears to show a good result, one will recall the discrepancy between design and model base shears (Figure 14), which influences the response. Furthermore, it will be demonstrated later that there is an underestimation of the required strength due to horizontal accelerations and an overestimation of P-delta effects. It should be also noted that compared to DDBD the match of the predicted and observed shape of the drift profile is not so good. The reason for this is rather simple in that FBD does not consider that the drift profile resulting from inelastic displacements differs from the drift profile resulting from elastic displacements. Therefore the drift profile from design is dominated by the fundamental mode elastic drift profile, which does not match the real behaviour of the structure in the inelastic range.

Table 4. Maximum inter-storey drifts.

\begin{tabular}{|l|c|c|c|}
\hline $\begin{array}{c}\text { Design } \\
\text { method }\end{array}$ & $\begin{array}{c}\text { Maximum } \\
\text { design drift } \\
(\%)\end{array}$ & $\begin{array}{c}\text { Maximum mean } \\
\text { NTHA drift } \\
(\%)\end{array}$ & $\begin{array}{c}\text { Error } \\
(\%)\end{array}$ \\
\hline DDBD & 2.46 & 2.28 & -0.08 \\
\hline FBD & 2.62 & 2.46 & -0.07 \\
\hline
\end{tabular}

From Table 4 it would appear that both methods perform equally well and this would indeed be true for the case study building that has been examined. However, the astute reader will have observed that the two design methods treat P-delta effects in very different ways. In DDBD the increase in design base shear, to account for P-delta effects, was only $5.8 \%$. On the hand the increase in base shear following the FBD approach, in accordance with NZS1170.5, is $19.4 \%$. Furthermore, the FBD approach also requires the designer to increase the maximum drifts as well as increasing the base shear. Therefore, it appears that one of the two methods is not accurately capturing the real extent of P-delta effects and further investigation is required (see Section 7).

At this point, some discussion of material strain limits is necessary. During the Force-Based Design of the case study structure, no consideration was given to material strain limits. This is justified as the material strain limits do not affect the design method in terms of its ability to accurately predict displacements and deformations. As mentioned previously there are two areas where material strain limits must be considered; (i) at the base of the walls and (ii) in the coupling beams. Considering the wall material strains, both DBD12 [Sullivan et al., 2012] and NZS3101 take a similar approach in determining material strains and as such they will not be consider. Furthermore, the exact material strain limits will not be discussed as they relate to the desired performance level and a discussion on these aspects is beyond the scope of this paper.

For coupling beam material strain limits, there is a significant discrepancy between the approach taken in this paper for DDBD and that of NZS3101. In this paper a reinforcing strain limit of $4 \%$ was established and this could then be related to coupling beam deformation through Equation 7. In this approach the coupling beam deformation at the material strain limit is strongly dependent on the coupling beam geometry. This is similarly reflected in the approaches of Paulay [2002] and Priestley et al. [2007]. The NZS3101 approach is to set a material strain limit by limiting the shear strain to 0.035 radians.

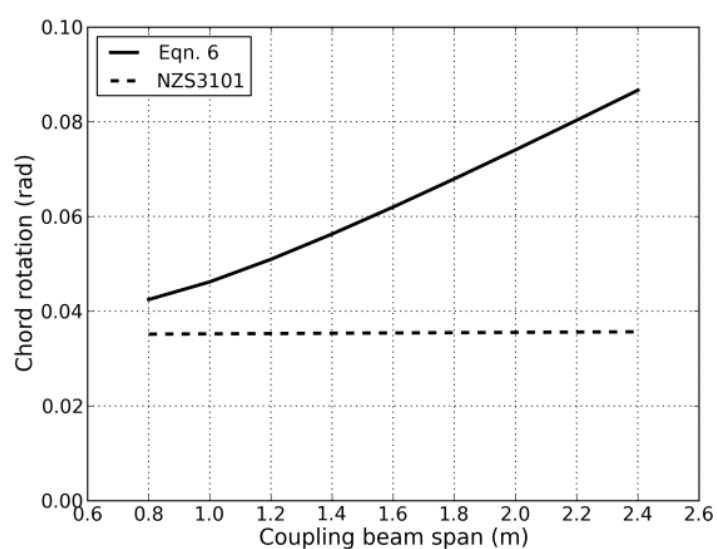

Figure 17: Comparison of allowable coupling beam chord rotations using different approaches to material strain limits.

This approach of setting a flat limit on shear strain does not seem valid in light of how dependent material strains are on geometry. Furthermore, it is well known that diagonally reinforced coupling beams behave like a truss [Paulay \& Binney, 1974] and therefore it does not seem appropriate to consider separate flexural and shear deformations. Figure 17 shows a comparison between the chord rotations at the material limit state strains for the coupling beam used in the case study structure for the two different approaches, but with the span varying from $0.8 \mathrm{~m}$ to $2.4 \mathrm{~m}$.

\section{INVESTIGATION INTO P-DELTA EFFECTS}

To determine which method, if either, is treating P-delta effects correctly, additional analyses have been run for the two structures designed using DDBD and FBD. For the additional analyses the gravity loads acting on the P-delta frames (refer Figure 12) have been removed. Figure 18 shows the mean NTHA drift profiles for both design methods, with and without P-delta loads. It can be seen that the effect of the Pdelta loads is rather small and therefore the NZS1170.5 method appears to be grossly over-conservative with regard to P-delta effects. The increase in maximum drifts due to P-delta effects are $0.96 \%$ and $3.1 \%$ for DDBD and FBD designed buildings respectively.

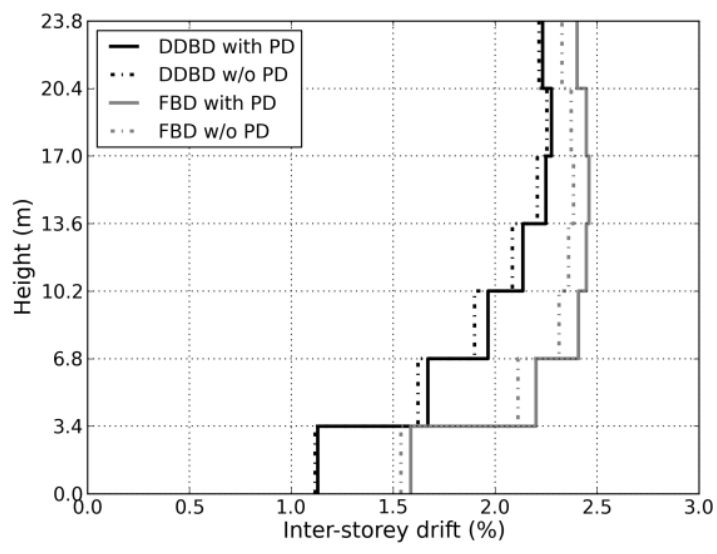

Figure 18: Comparison of inter-storey drifts for the buildings analysed with and without P-delta effects. 
To investigate further, both designs were repeated without consideration of P-delta effects. This could be equated to designing a structure that has mass acting in the horizontal direction only (except for that which causes the axial force on the walls). While this is a somewhat unrealistic structure, it is useful for testing the FBD method for cases where P-delta effects are not expected to be significant. The key design outputs for the structures designed using FBD, without consideration of P-delta effects, are provided in Tables 5 and 6 for DDBD and FBD respectively.

Table 5. Key design outputs from DDBD for structure designed without consideration of P-delta effects.

\begin{tabular}{|c|c|}
\hline$T_{l}(\mathrm{~s})$ & 1.51 \\
\hline Max. drift $(\%)$ & 2.47 \\
\hline$V_{b}(\mathrm{kN})$ & 3068 \\
\hline$\rho_{w}(\%)$ & 1.38 \\
\hline$N_{c} / f^{\prime} A_{g}$ & 0.115 \\
\hline$N_{t} / f_{y} A_{s}$ & 0.144 \\
\hline$A_{s, C B}\left(\mathrm{~mm}^{2}\right)$ & 1280 \\
\hline
\end{tabular}

Table 6. Key design outputs from FBD for structure designed without consideration of P-delta effects.

\begin{tabular}{|c|c|}
\hline$T_{l}(\mathrm{~s})$ & 1.48 \\
\hline Max. drift $(\%)$ & 2.12 \\
\hline$V_{b}(\mathrm{kN})$ & 1410 \\
\hline$\rho_{w}(\%)$ & 0.385 \\
\hline$N_{c} / f^{\prime} A_{g}$ & 0.112 \\
\hline$N_{t} / f_{y} A_{s}$ & $\mathrm{NA}^{*}$ \\
\hline$A_{s, C B 7}\left(\mathrm{~mm}^{2}\right)$ & $716(819)$ \\
\hline$A_{s, C B 6}\left(\mathrm{~mm}^{2}\right)$ & $1196(1196)$ \\
\hline$A_{s, C B 5}\left(\mathrm{~mm}^{2}\right)$ & $1615(1548)$ \\
\hline$A_{s, C B 4}\left(\mathrm{~mm}^{2}\right)$ & $1615(1732)$ \\
\hline$A_{s, C B 3}\left(\mathrm{~mm}^{2}\right)$ & $1615(1564)$ \\
\hline$A_{s, C B 2}\left(\mathrm{~mm}^{2}\right)$ & $716(716)$ \\
\hline$A_{s, C B I}\left(\mathrm{~mm}^{2}\right)$ & $804(3)$ \\
\hline
\end{tabular}

$*$ Walls never go into net tension and so no value is provided.

The newly designed structures were analysed in SeismoStruct and the results in terms of inter-storey drift are compared with the design drifts in Figure 19. In this case it can be seen that FBD is significantly non-conservative. The maximum mean drift found from the NTHA is $2.72 \%$, which is $22 \%$ greater than the design drift of $2.12 \%$. By comparison, for the DDBD structure, design drifts still match closely to those found from NTHA. It can therefore be concluded that the reason the initial Force-Based Design met its design expectations so well is largely due to an erroneous allowance for P-delta effects. This is clearly not an appropriate way to design structures for earthquake resistance and although in this case the structure performed adequately, this may not be case the for other coupled wall buildings design using FBD.

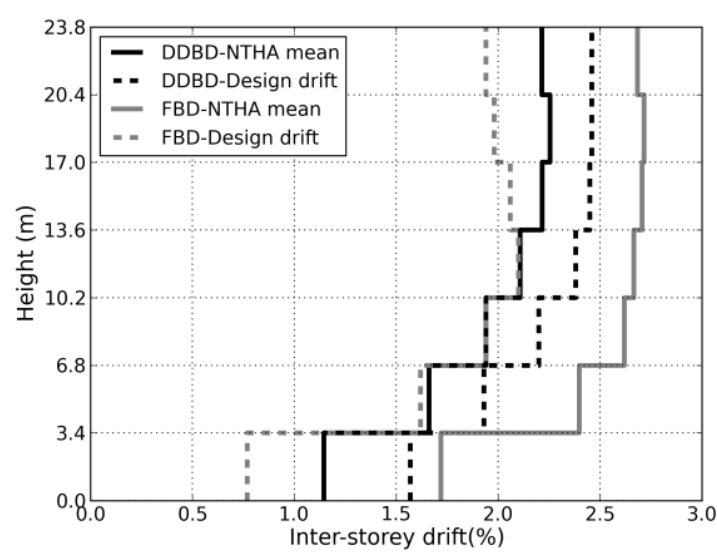

Figure 19: Comparison of design and NTHA mean interstorey drifts for buildings designed and analysed without P-delta effects.

\section{CONCLUSIONS}

This paper has compared DDBD and FBD in accordance with NZS1170.5 and NZS3101 in their application to the design of $\mathrm{RC}$ coupled walls. This has been done by considering a simple case study structure, which was designed using both methods. Application of the code-approach permitted critical examination of some of the current code equations. Numerical models of the designed structures were subjected to non-linear time-history analysis to assess the performance of the design methods. The adequacy of each design approach was based on how accurately the design method could estimate displacements and deformations, which can then be related to code prescribed inter-storey drift and material strain limits. From this work the following conclusions can be drawn:

1) The method of determining the stiffness of coupling beams, in particular the shear area, in accordance with NZS3101 was shown to be problematic. The approach, which considers the inelastic response of a coupling beam, is incompatible with the accompanying elastic analysis that must be carried out. Furthermore, the approach is iterative, making it rather time consuming.

2) The use of distributed-plasticity fibre-section beam elements can simplify the modelling of coupled walls for NTHA. The two main advantages relevant to coupled walls are that (i) moment-axial force interaction is accounted for implicitly and (ii) axial elongation of the walls (due to flexure) is captured. In addition, diagonal truss elements were shown to reproduce experimental test results well.

3) DDBD is able to accurately estimate the displacements and deformations of a coupled wall structure subjected to seismic excitation. This was shown through the design of a case study structure and is further supported by Fox [2013].

4) FBD applied to the case study structure, resulted in a design that accurately estimated the maximum inter-storey drift found through NTHA. However, it was subsequently shown that when allowances for P-delta effects were removed (from both design and analysis) the design approach was significantly non-conservative.

5) P-delta effects in RC coupled walls were shown to have only a minor effect on increasing displacements during seismic response. The allowance for P-delta effects prescribed by NZS1170.5 appears to be too severe for coupled walls and does not match the true response of the structure. 
6) The material strain limit for diagonally reinforced coupling beams prescribed in NZS3101 does not account for the geometry of the coupling beam. This was shown to be illogical as the material strains in a coupling beam are highly dependent on geometry. As a result the current material strain limit may be too restrictive for longer span coupling beams and this could be particularly relevant in the assessment of existing RC coupled wall structures.

7) Further research is required to evaluate the performance and review design methods for coupled wall systems in which not all of the coupling beams yield. This structural response is likely at low seismic intensities and for coupled walls with large aspect ratio coupling beams.

In closing, serious consideration must be given to updating the code design approach for RC coupled walls. The current FBD method is known to be of limited accuracy and based on a number of flawed concepts. DDBD appears to be a valid alternative and its incorporation into future code revisions would represent a good step towards incorporating state-ofthe-art knowledge into current design practice.

\section{ACKNOWLEDGMENTS}

The authors would like to thank Professor Nigel Priestley for his comments regarding the Direct Displacement-Based Design of coupled walls. The two reviewers are also thanked for the recommendations they provided to improve the paper. The first author would like to acknowledge the funding provided by the MEEES programme (www.mees.org).

\section{LIST OF SYMBOLS}

$A_{d} \quad$ Area of diagonal reinforcing in coupling beam from NZS3101

$A_{g} \quad$ Gross area of wall section

$A_{s, C B} \quad$ Area of diagonal reinforcing in coupling beam

$A_{\text {Shear }} \quad$ Shear area of coupling beams from NZS3101

$C \quad$ Coefficient accounting for hysteretic behaviour in Pdelta effects

$C(T) \quad$ Ordinate of the elastic site hazard spectrum from NZS 1170.5

$C_{d}(T)$ Horizontal design action coefficient from NZS1170.5

$d_{b} \quad$ Reinforcing bar diameter from NZS3101

$E_{s} \quad$ Young's modulus for reinforcing steel

$f_{c}^{\prime} \quad$ Specified (28 day) concrete compression strength

$f_{s, l s} \quad$ Reinforcing stress at limit state strain

$f_{u} \quad$ Ultimate strength of reinforcing

$f_{y} \quad$ Yield strength of reinforcing

$G \quad$ Shear modulus

$H_{C F} \quad$ Height of contraflexure

$H_{e} \quad$ Effective height of equivalent SDOF system

$H_{n} \quad$ Height to uppermost seismic mass

$h_{C B} \quad$ Coupling beam depth

$h_{i} \quad$ Height of level $i$

$K_{e} \quad$ Effective stiffness of equivalent SDOF system

$k_{\mu} \quad$ Ductility reduction factor from NZS1170.5

$L \quad$ Coupling beam span from NZS3101

$L_{C B} \quad$ Coupling beam span

$L_{P} \quad$ Plastic hinge length

$L_{S P} \quad$ Strain penetration length

$L_{w} \quad$ Wall length

$M_{\text {OTM }} \quad$ Overturning moment

$M_{w} \quad$ Required moment capacity of an individual wall $m_{e} \quad$ Effective mass of equivalent SDOF system

$N(T, D) \quad$ Near fault factor from NZS1170.5

$N_{c} \quad$ Maximum compression force in wall

$N_{t} \quad$ Maximum tension force in wall

$n \quad$ Number of storeys

PSA Pseudo spectral acceleration

$R \quad$ Factor to reduce design displacement spectrum from $5 \%$ viscous damping to desired damping ratio

$R_{u} \quad$ Return period factor from NZS1170.5

$S D \quad$ Spectral displacement

$S_{P} \quad$ Structural performance factor from NZS1170.5

$T \quad$ Period of vibration

$T_{1} \quad$ Period of vibration of fundamental mode

$T_{e} \quad$ Effective period of equivalent SDOF system

$t_{C B} \quad$ Coupling beam thickness

$t_{w} \quad$ Wall thickness

$V_{C B, i} \quad$ Shear force in coupling beam at level $i$

$V_{C B, l s} \quad$ Shear force in coupling beam at relevant limit state

$V_{C B, y} \quad$ Shear force in coupling beam at yield

$V_{b} \quad$ Design base shear

$V_{d} \quad$ Shear force in coupling beam at yield from NZS3101

Z Hazard factor from NZS1170.5

$\mathrm{Z} \quad$ Vertical distance between sets of diagonal reinforcing at the coupling beam to wall interface

$\alpha \quad$ Angle between diagonal reinforcing and longitudinal axis of coupling beam

$\beta \quad$ Coupling ratio

$\beta_{c r} \quad$ Maximum crack inclination in RC wall

$\beta_{P-\Delta} \quad$ Factor for P-delta calculations from NZS3101

$\Delta_{d} \quad$ Design displacement of equivalent SDOF system

$\Delta_{i, l s} \quad$ Displacement of level $i$ at relevant limit state

$\Delta_{i, y} \quad$ Displacement of level $i$ at yield

$\Delta_{s} / \Delta_{f} \quad$ Ratio of shear to flexural deformations

$\Delta_{y} \quad$ Yield displacement of equivalent SDOF system

$\delta_{v} \quad$ Shear deformation of coupling beam at yield from NZS3101

$\delta_{y} \quad$ Axial elongation of diagonal reinforcing in tension at yield from NZS3101

$\varepsilon_{m} \quad$ Mean axial strain

$\varepsilon_{s, l s} \quad$ Limit state reinforcing strain

$\varepsilon_{s, u} \quad$ Reinforcing strain at maximum stress

$\varepsilon_{y} \quad$ Yield strain of reinforcing

$\theta_{c} \quad$ Code (or otherwise defined) drift limit

$\theta_{C B, l s} \quad$ Coupling beam limit state rotation

$\theta_{C B, y} \quad$ Coupling beam yield rotation

$\theta_{p C W} \quad$ Design plastic rotation

$\mu \quad$ Displacement ductility

$\mu_{C B} \quad$ Coupling beam displacement ductility demand

$\mu_{s y s} \quad$ System displacement ductility demand

$\mu_{w} \quad$ Wall displacement ductility demand

$\xi \quad$ Damping ratio

$\xi_{C B} \quad$ Coupling beam equivalent viscous damping ratio

$\xi_{\text {sys }} \quad$ System equivalent viscous damping ratio

$\xi_{w} \quad$ Wall equivalent viscous damping ratio

$\rho_{w} \quad$ Wall reinforcing ratio

$\phi \quad$ Curvature

$\phi_{w, l s} \quad$ Wall curvature at relevant yield state

$\phi_{w, y} \quad$ Wall yield curvature

$\omega \quad$ Angular frequency

$\omega_{\theta} \quad$ Higher mode factor 


\section{REFERENCES}

$1 \quad$ NZS1170.5 [2004], Structural Design Actions - Part 5 Earthquake Actions, Standards New Zealand (Code and Commentary).

2 NZS3101 [2006], Concrete Structures Standard - Part 1 (Code) and Part 2 (Commentary), Standards New Zealand.

3 Priestley, M.J.N. [1993] "Myths and fallacies in earthquake engineering - conflicts between design and reality," Bulletin of the New Zealand National Society for Earthquake Engineering, 26(3). 329-341.

4 Priestley, M.J.N. [2003], Myths and Fallacies in Earthquake Engineering, Revisited. The $9^{\text {th }}$ Mallet Milne Lecture, IUSS Press, Pavia.

5 Priestley, M.J.N., Calvi, G.M. and Kowalsky, M.J. [2007] Displacement-Based Seismic Design of Structures, IUSS Press, Pavia, Italy.

6 Paulay, T. [1969] "The coupling of shear walls," Doctoral Thesis, University of Canterbury, New Zealand.

7 Paulay, T. and Binney, J.R. [1974] "Diagonally reinforced coupling beams of shear walls," Publication SP-42, American Concrete Institute. 579-598.

8 Paulay, T. [2002] "The displacement capacity of reinforced concrete coupled walls," Engineering Structures. 24. 1165-1175.

9 Sullivan, T.J., Calvi, G.M., Priestley, M.J.N. (Editors) [2012] A Model Code for the Displacement-Based Seismic Design of Structures DBD12, IUSS Press, Pavia, Italy.

10 Fox, M.J. [2013] "Seismic Design of Coupled Walls," Masters Thesis, ROSE programme, UME School, IUSS Pavia, Italy.

11 Sullivan, T.J., Priestley, M.J.N. and Calvi, G.M. [2005] "Development of an innovative seismic design procedure for frame-wall structures," Journal of Earthquake Engineering, 9(Special Issue 2), 279-307.

12 Sullivan, T.J., Priestley, M.J.N. and Calvi, G.M. [2006] "Direct displacement based design of frame-wall structures," Journal of Earthquake Engineering, 10(Special Issue 1), 91-124.

13 Priestley, M.J.N., Seible, F. and Calvi, G.M. [1996] Seismic Design and Retrofit of Bridges, Wiley, New York.

14 Fox, M.J., Sullivan, T.J. and Beyer, K. [2014] "Capacity design of coupled RC walls," Journal of Earthquake Engineering, 18(5), 735-758.

15 Canterbury Earthquakes Royal Commission [2012] Canterbury Earthquakes Royal Commission (Te Komihana Rūwhenua o Waitaha) Final Report: Volume 1, Christchurch, New Zealand.

16 Grant, D.N., Blandon, C.A. and Priestley, M.J.N. [2005] Modelling Inelastic Response in Direct DisplacementBased Design, Report 2005/03, IUSS Press, Pavia, Italy.

17 Pennucci, D., Sullivan, T.J. and Calvi, G.M. [2011] "Displacement reduction factors for the design of medium and long period structures," Journal of Earthquake Engineering, 15(Supp. 1), 1-29.

18 Seismosoft [2013] SeismoStruct: A Computer Program for Static and Dynamic Nonlinear Analysis of Framed Structures, Version 6, http://www.seismosoft.com.
19 Menegotto, M. and Pinto, P.E. [1973] "Method of analysis for cyclically loaded R.C. plane frames including changes in geometry and non-linear behaviour of elastic elements under combined normal force and bending," Symposium on the Resistance and Ultimate Deformability of Structures Acted on by Well Defined Repeated Loads, International Association for Bridge and Structural Engineering, Zurich, Switzerland, 15-22.

20 Yazgan, U. and Dazio, A. [2010] "Critical aspects of finite element modeling of RC structures for seismic performance assessment," Proceedings of the $9^{\text {th }}$ U.S. National and $10^{\text {th }}$ Canadian Conference on Earthquake Engineering, Paper No. 404, Toronto, Canada.

21 Petrini, L., Maggi, C., Priestley, M.J.N. and Calvi, G.M. [2008] "Experimental verification of viscous damping modeling for inelastic time history analyzes [sic]," Journal of Earthquake Engineering, 12(Supp 1). 125-145.

22 Correia, A.A., Almeida, J.P. and Pinho, R. [2013] "Seismic energy dissipation in inelastic frames: understanding state-of-the-practice damping models," Structural Engineering International, 2/2013. 148-158.

23 Beyer, K., Simonini, S., Constantin, R. and Rutenburg, A. [2014] "Seismic shear distribution among interconnected cantilever walls of different lengths," Earthquake Engineering and Structural Dynamics, published online DOI 10.1002/eqe.2403.

24 Beyer, K., Dazio, A. and Priestley, M.J.N. [2011] "Shear deformations of slender reinforced concrete walls under seismic loading," ACI Structural Journal. 108(2). 167177

25 Dazio, A., Beyer, K. and Bachmann, H. [2009] "Quasistatic cyclic tests and plastic hinge analysis of RC walls," Engineering Structures. 31(7). 1556-1571.

26 Maley, T.J., Sullivan, T.J., Lago, A., Roldan, R. and Calvi, G.M. [2013] Characterising the Seismic Behaviour of Steel MRF Structures, Report 2013/02, IUSS Press, Pavia, Italy. 